\title{
Structural integrity monitoring of onshore wind turbine concrete foundations
}

\author{
Magnus Currie ${ }^{1 *}$, Mohamed Saafi ${ }^{2 *}$, Christos Tachtatzis ${ }^{3}$ and Francis Quail ${ }^{4}$
}

${ }^{1}$ E D P Renewables Ltd, Edinburgh, EH2 2BY, UK

${ }^{2}$ Department of Engineering, Lancaster University, Lancaster, LA1 4YR, UK

${ }^{3}$ School of Engineering, University of Glasgow, Glasgow, G12 8QQ, UK

${ }^{4}$ Aramco Technology Office, Aberdeen, AB32 6FE

\section{Abstract}

Signs of damage around the bottom flange of the embedded ring were identified in a large number of existing onshore concrete foundations. As a result, the embedded ring experienced excessive vertical displacement. A wireless structural integrity monitoring (SIM) technique was developed and installed in the field to monitor the stability of these turbines by measuring the displacement patterns and subsequently alerting any significant movements of the embedded ring. This was achieved by using wireless displacement sensors located in the bottom of the turbine. A wind turbine was used as a test bed to evaluate the performance of the SIM system under field operating conditions. The results obtained from the sensors and supervisory control and data acquisition (SCADA) showed that the embedded ring exhibited significant vertical movement especially during periods of turbulent wind speed and during shut down and start up events. The measured displacement was variable around the circumference of the foundation as a result of the wind direction and the rotor uplift forces. The excessive vertical movement was observed in the side where the rotor is rotating upwards. The field test demonstrated that the SIM technique offers great potential for improving the reliability and safety of wind turbine foundations. 
$24 \quad$ Keywords

25 Onshore wind turbine, Concrete foundations, Forensic investigation, Structural integrity, 26 Monitoring.

27 *Corresponding authors (magnus.currie@gmail.com) and $\underline{\text { m.saafi@lanacaster.ac.uk }}$

\section{Introduction}

31 Wind is currently considered as one of the most cost-effective large-scale alternative energy sources. In the UK, onshore wind farm developments make up the largest proportion of wind generating capacity, with offshore production beginning to significantly grow. Structural integrity monitoring (SIM) has become an integral part of onshore wind farm asset management programs to ensure safety and reliability. Like any other structure, a wind turbine is prone to damage from fatigue, environmental exposures and construction defects. Structural problems that can affect the operation of a wind turbine could include delamination of the blade and failure of tower and foundation systems. The foundation failure is often a slow process, developing over a number of months or even years. However, recently, excessive vertical movement has been reported in several onshore wind turbine concrete foundations with embedded ring as a connection system [1]. These embedded rings have been recorded to be moving up to $20 \mathrm{~mm}$ or more in some extreme cases and this could lead to catastrophic collapse of the turbines. Whilst there is no published data on the exact number of failures due to commercial reasons, it is thought that the problem is widespread given the popularity of the foundation system worldwide. 
There are 4000 wind turbines of the type operational worldwide with further manufacturers also using the foundation type.

SIM systems are widely used in various components, structures and sub systems of a wind turbine to allow proactive maintenance and ensure reliability and availability of the machine [2]. For example, SIM systems have been applied to wind turbines to monitor blade delamination using fibre optic sensors [3] and blade icing using thermal and acoustic sensors [4]. Wireless monitoring technologies have also been suggested in order to limit the extra weight added to the blade [5]. The turbine tower generally has an extremely low failure rate [6] and hence there has been limited SIM applications. One study used strain gauge arrays to monitor the tower at a number of locations from the bottom to the top of the tower [7]. The array layout meant changes in tower modes due to wind direction could be monitored. In addition to new sensor technologies, the application of wireless communication has made SIM more practical and affordable. Research has been undertaken to assess the opportunities to apply wireless SIM to many wind turbine parts including the rotor and tower [8].

There are a number of different foundations types used globally, and as foundations sizes increase as turbines become larger, it becomes more important that foundations are designed and monitored effectively, both during construction and throughout their operational lifetime [9]. However, currently there are no real time SIM systems in place for the operator to assist in its monitoring of the problem, mapping or quantifying the movement patterns of the foundation and subsequently alerting any potential failure.

In this paper, we present a wireless SIM system for onshore wind turbine concrete foundations. First, a site investigation was conducted i) to identify the main damage mechanisms responsible for the excessive vertical movement of the embedded ring, ii) to 
determine the monitoring system requirements and iii) to develop movement alarm bands. Then, a wireless sensor array system was designed and deployed in one wind turbine foundation to monitor its vertical movement under normal turbine operating conditions. The reliability of the monitoring system and the response of the individual sensors were assessed and compared to SCADA data. The structural response of the concrete foundation was quantified under turbine operational conditions and the effect of wind speed and direction on the vertical movement of the foundation was analysed.

\section{Wind turbine test bed}

The onshore wind turbine concrete foundations with embedded ring shown in Fig. 1 are widely used around the world. These types of foundations are the subject of this study with respect to vertical movement. Several wind farms were visited to identify the main cause of this vertical movement using Endoscopic filming through boreholes created in the foundations. The Endoscopic filming showed significant voids filled with water under the flange of the embedded ring. Significant erosion was also observed on the upper side of bottom flange due to the uplift forces placed on the foundation by the rotor. These voids have caused excessive vertical movement of the ring, leading to concrete cracking (Fig. 2) and failure of the water proofing system.

Based on the site observations, the followings vertical movement bandings were used as warning signals. Normal operation allows 1-2 mm of elastic stretching of the tower, 3-4 mm of vertical movement is a sign that there is voids in the foundation and finally movement over 5 $\mathrm{mm}$ is deemed to be serious and further investigations are necessary. When the SIM records a movement of $5 \mathrm{~mm}$ or greater, the foundation requires remediation. Accordingly, a sensor sensitivity of $0.1 \mathrm{~mm}$ was adopted for the SIM system. 
The wind turbine test bed used in this investigation was a modern 2.0 MW pitch regulated variable speed machine and in operation for at least five years. The exact location and turbine model are confidential due to a non-disclosure agreement with the operator. The foundation consisted of an octagonal reinforced concrete slab with an embedded steel ring connection system. Fig. 3 shows the geometry of the foundation. The foundation was designed to support a $67 \mathrm{~m}$-hub tower equipped with a rotor of $80 \mathrm{~m}$ in diameter.

\section{Wireless SIM methodology}

Currently, monitoring of vertical movement involves visits by technicians to the site to take manual readings of the foundation movement. This can be problematic during winter when the site is often partially or fully inaccessible due to snow cover and/or high winds. Furthermore, the greatest displacement occurs during higher wind speeds and this cannot be guaranteed during each visit. Consequently, a SIM solution needed to allow more accurate and detailed real time movement data. The SIM system presented in this paper was designed to provide a much greater level of data to the engineering team than was previously available using site investigation techniques alone.

In this project, linear variable differential transformer (LDVT) sensors were adopted to measure the vertical movement of the embedded ring. LVDTs sensors are a very effective method for measuring movement and have been used in a number of SIM applications in civil engineering structures [10]. They are robust and immune to large magnetic field surrounding the high voltage cables coiled in the foundation. LVDTs with a gauge length of $50 \mathrm{~mm}$ were selected as being the optimum size and having a suitable accuracy for the displacement measurements. 
As shown in Fig. 4a, four LVDT sensors were installed under the top flange of the embedded ring. Each LVDT was equipped with an off-the-shelf wireless communication node set to measure displacement at a frequency of $1 \mathrm{~Hz}$. This rate was deemed to be sufficient for the relatively slow movement of the turbine tower. The nodes were equipped with a $2.4 \mathrm{GHz}$ CC2420 wireless radio chip from Texas Instruments, which is IEEE 802.15.4 compliant. The transmission power was set at $0 \mathrm{dBm}$ while the receiver sensitivity of radio chip is $-95 \mathrm{dBm}$. The wireless gateway device consisted of an off-the-shelf low cost Raspberry Pi microcomputer, a standard 4GB SD memory card and a small size battery pack, which acts as a UPS.

The sensors were positioned equidistant around the foundation (see Fig. 4a). The measurement points are numbered on the figure as 1 NW (North West), 2 NE (North East), 3 SE (South West) and 4 SW (South West). These points were selected because the prevailing wind conditions on the site were south-westerly in nature. Using these measurement points, the sensor array would capture the displacement on planes parallel and perpendicular to the prevailing wind. The LVDT sensors were installed to measure the displacement between the static concrete foundation and the embedded ring. It was essentially measuring the movement of the embedded ring at the connection with the tower. Retort stands were used to keep the sensors with a heavy weight base and the attachments were locked in position using thumbscrews, preventing any movement during operation. The LVDTs were set half compressed, allowing vertical upwards and downwards movements to be recorded. The LVDT installed in the foundation had a maximum stroke of $50 \mathrm{~mm}$; hence they were installed at a set position of $25 \mathrm{~mm}$. Fig. 4-b shows the sensor location along with the method of anchoring the sensor.

The monitoring of the foundation was carried out over a period of 2 months to evaluate the performance of the SIM system under field conditions using a remote data acquisition system. 
SCADA data was collected and correlated with the measured displacements. The data included wind speed, wind direction and rotational speed of the rotor. Maximum and minimum wind speed and standard deviations were obtained for each variable and used to evaluate the response of the foundation under the turbine operating conditions. The recorded displacements were compared with the maximum rotational speed since this was the key-influencing factor on the displacement of the foundation

\section{Results and discussion}

\subsection{Effect of rotor and wind speed on the vertical displacement of the embedded ring}

Fig. 5a depicts the structural response of the embedded ring subjected to dynamic loading during the turbine operating conditions over a period of $30 \mathrm{~min}$. As can be seen, large drop offs in the maximum rotor speed were observed. This was due to the drop in the wind speed. The standard deviation of mean rotor speed exhibited peaks higher than 0.6 , suggesting a period of turbulence. The spikes in the ring displacement occurred in line with the standard deviation peak. This means that during periods of turbulent wind, the rotor is subjected to sudden acceleration and deceleration. This sudden change in the momentum resulted in the ring lifting and falling of the embedded ring. This suggests that the embedded ring experiences vertical displacement during sudden acceleration and deceleration of the rotor resulting from the change in the wind speed and direction. Vertical displacement could also occur during shut down and start up events as this produces sudden acceleration and deceleration of the rotor. Figure 5b shows a number of peak displacements up to $5 \mathrm{~mm}$. In this case, some of the peaks appeared to be related to the rotor speed standard deviation e.g. turbulence, whilst others, such as at 19:12, appeared to be related to the maximum rotor speed peaks. 
As shown in Fig. 6, the embedded ring experienced significant vertical displacement at

159

160

161

162

163

164

165

166

167

168

169

170

171

172

173

174

175

176

177

178

179

180

high wind speeds. Serious displacement was deemed by the operator to be any movement over 5 $\mathrm{mm}$ in magnitude. Most of the vertical displacement was witnessed in the rising direction with the tower settling back downwards after rotor speeds stabilised.

A significant period of displacement over approximately 5 min was observed between 18:00 and 18:05. The amber and red warning lines at $3 \mathrm{~mm}$ and $5 \mathrm{~mm}$ respectively indicate the warning bands required by the operator for analysis. At 18:01 there was a large drop off in the rotor speed, which triggered large upward then large downward displacements of over $5 \mathrm{~mm}$, breaching the red warning line. Five small displacement peaks between $0.5 \mathrm{~mm}$ and $1.5 \mathrm{~mm}$ were also observed. Each of these peaks correlated with the rotor speed standard deviation peaks as shown in Fig. 6.

High wind speeds also resulted in significant vertical displacement of the ring as indicated in Fig. 7. This illustrates one of the many variable periods of displacement observed during the monitoring period. As can be seen, rising and falling of the ring around $7 \mathrm{~mm}$ through 6 prescribed cycles were observed over a period of $15 \mathrm{~min}$. The overall displacement pattern correlated roughly with the maximum rotor speed peaks and troughs as well as with the mean rotor speed standard deviation peaks. It is clear that there was a significant ring movement tracking the significant fluctuation in the rotor speed, particularly between 19:18 and 19:25, with a full cycle occurred approximately every minute. This cyclic (rise and fall) movement would be evident to an observer on site. The displacement during this period travelled through all three warning bands, resulting in red warning alerts, which would result in a warning alarm.

\subsection{Effect of wind direction on the vertical displacement of the embedded ring}

Figure 8a shows the effect of the wind direction on the vertical displacement of the embedded ring. As shown, the southwesterly wind was turbulent causing rotor speed changes between 14.5 
$181 \mathrm{rpm}$ and $16.5 \mathrm{rpm}$. As previously discussed, the displacement peaks correlated approximately

182 with periods of the high mean rotor speed standard deviation. The NW and SW sensors picked

183 up exactly the same movements. However, the sensor NW, orthogonal to the wind direction, 184 recorded larger displacements at every peak. This was the result of the wind direction and 185 ultimately the position of the rotor. It is likely that the side where the wind hit will be pushed up 186 a little but the greatest vertical movement was observed in the side where the rotor is rotating upwards as a result of the uplift force experienced on the NW side of the foundation. displacement was variable around the circumference of the ring as a result of the wind direction and the rotor uplift forces. The NW side of the ring exhibited higher displacement as compared to SW and SE sides. The response of the sensor in the SE corner was slightly below zero much of the time suggesting that the foundation has eroded allowing a negative displacement below the

194 level the sensors were set at.

195

196

197

198

199

200

201

202

203

Figure 8b shows the displacement recorded by the NW, SW and SE sensors during a major dip in the rotor speed. The NE sensor provided a corrupted signal. It appeared that the

\section{Conclusions}

The potential of using a low cost displacement sensor array to measure vertical movement of onshore wind turbine foundations with embedded ring is presented in this paper. The system is simple and relatively easy to install. The ability of the system to capture displacement, regardless of wind direction demonstrates the potential for further development into a full SIM system complete with user interface and alerting toolset. The site investigation identified several damage mechanisms responsible for the excessive movement of the embedded steel ring. Structural cracks were commonly observed in the concrete pedestals. Water ingress through these cracks led to the formation of voids above and underneath the bottom flange of the 
embedded ring. The cyclic movement of the embedded ring led the erosion of the concrete and ultimately created these voids. The observed defects could have negative impact on the structural integrity of onshore wind turbines and as a result, the development of renewable energy could be hindered. Monitoring the progress of these defects is deemed necessary to prevent catastrophic failures.

Based on the results from the field test, the wireless SIM system picked up a number of varying movements including single and cyclic patterns. The Results also showed that the embedded ring experienced vertical movement on a number of occasions (red warning $5 \mathrm{~mm}$ or greater movement). The excessive displacements were observed during periods of turbulent wind speeds and during shut down and start up events. The wireless system presented herein limited the number of cables in the turbine and allowed data download without need to access the turbine. The system is flexible and could handle additional sensors, different sensors types and also variable frequency of readings. The SIM system has the potential to greatly impact the onshore wind energy industry by significantly reducing both the risk of catastrophic failure of the foundations and the energy supply disruptions.

\section{Acknowledgements}

This work has been funded by the EPSRC, project reference number EP/G037728/1.

\section{References}

1. Currie M, Quail F, Saafi M. Development of a robust structural health monitoring system for wind turbine foundations. in ASME Turbo Expo 2012. 2012. Copenhagen: ASME.

2. Schubel PJ, Crossley RJ, Boateng EKG, Hutchinson JR. Review of structural health and cure monitoring techniques for large wind turbine blades. Renewable Energy 2013; 51:113-123.

3. Bang HJ, HK Shin, YC Ju. Structural health monitoring of a composite wind turbine blade using fiber Bragg grating sensors, in Sensors and Smart Structures Technologies for Civil, Mechanical, and Aerospace Systems 2010; Spie-Int Soc Optical Engineering: Bellingham. 
4. $\quad$ Harper N. Detecting Ice on Wind-turbine Blades. Windpower Engineering 2011.

5. Taylor SG, Farinholt KM, Park G, Farrar CR, Todd MD. Application of a wireless sensor node to health monitoring of operational wind turbine blades 2009; Conference: 28th International Modal Analysis Conference ; February 1, 2010 ; Jacksonville, FL

6. Ribrant J, and Bertling LM. Survey of failures in wind power systems with focus on Swedish wind power plants during 1997-2005. Ieee Transactions on Energy Conversion 2007; 22(1): 167-173.

7. Benedetti M, Fontanari V, Zonta D, Structural health monitoring of wind towers: remote damage detection using strain sensors. Smart Materials \& Structures 2011. 20(5).

8. Swartz RA, Lynch JP, Zerbst S, Sweetman B, Rolfes R. Structural monitoring of wind turbines using wireless sensor networks. Smart Structures and Systems 2010; 6(3):183-196.

$9 \quad$ Wang P, Yan Y, Gui YT, Bouzid O, Ding Z. Investigation of Wireless Sensor Networks for Structural Health Monitoring. Journal of Sensors, 2012; 2012.

10. Ciang CC, Lee JR, Bang HJ. Structural health monitoring for a wind turbine system: a review of damage detection methods. Measurement Science \& Technology 2008; 19(12).

11. Texas Instruments. Single-Chip 2.4 GHz IEEE 802.15.4 Compliant and ZigBee Ready RF Transceiver (Rev. B) 2012 [cited 2013 Aug 4]; Available from:URL: http://www.ti.com/lit/ds/symlink/cc2420.pdf.

12. Di Franco F, Tachtatzis C, Graham B, Bykowski M, Tracey DC, Timmons NF, Morrison J. Current characterisation for ultra low power wireless body area networks. in Intelligent Solutions in Embedded Systems (WISES) 2010; 8th Workshop on. 2010; 91-96.

13. RaspberryPi. Raspberry Pi FAQs 2013 [cited 2013 17th July]; Available from: URL: http://www.raspberrypi.org/faqs. 


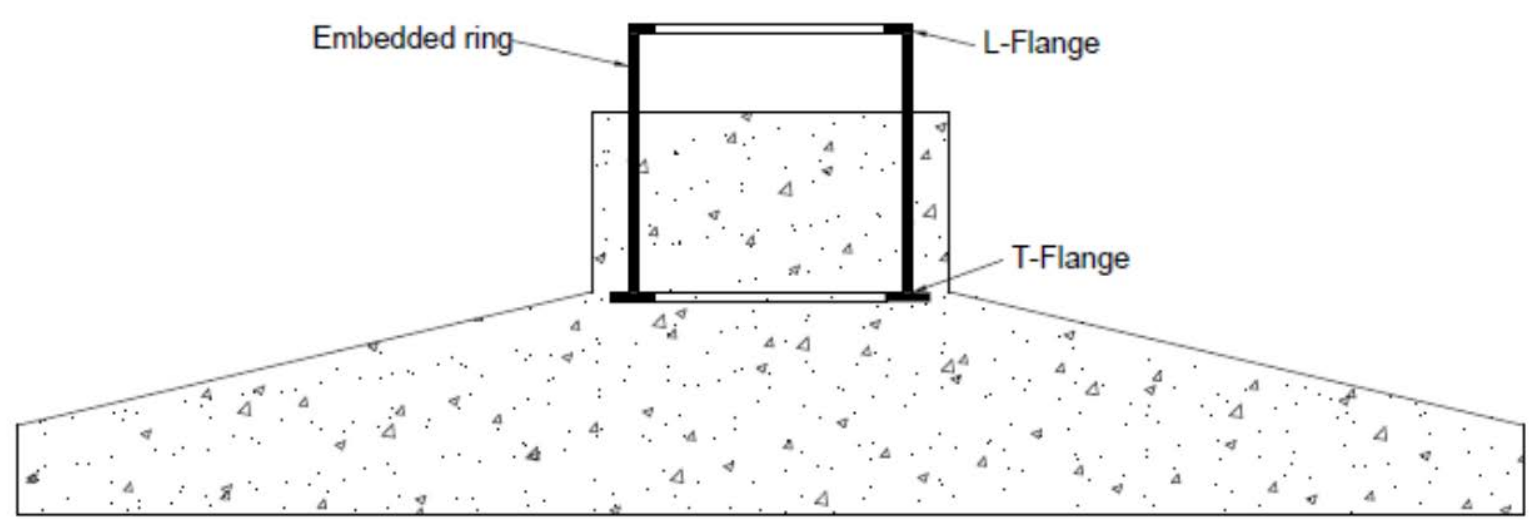

Fig.1: Typical onshore wind concrete foundation with embedded ring

296

297

298

299

300

301

302

303

304

305

306

307

308

309

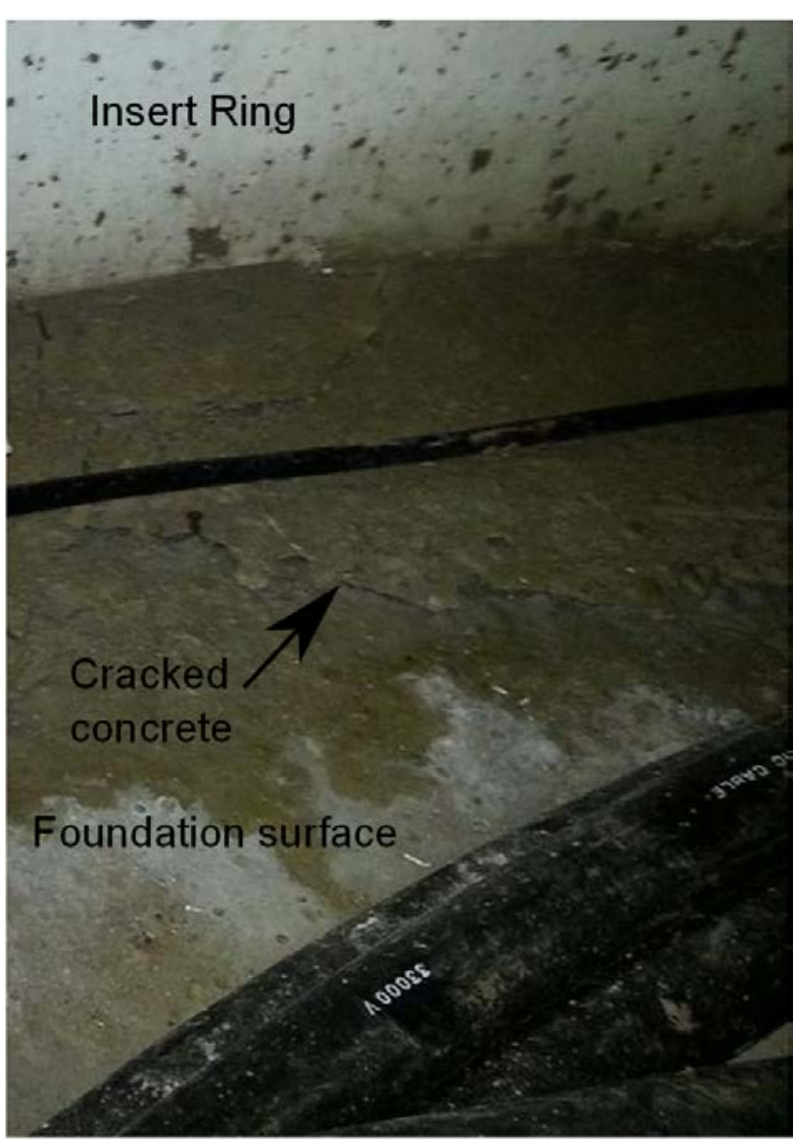


314 Fig. 2 Cracked concrete foundation as a result of excessive displacement of the embedded ring.

315

316

317

318

319

320

321

322

323

324

325

326

327

328

329

330

331

332

333

334

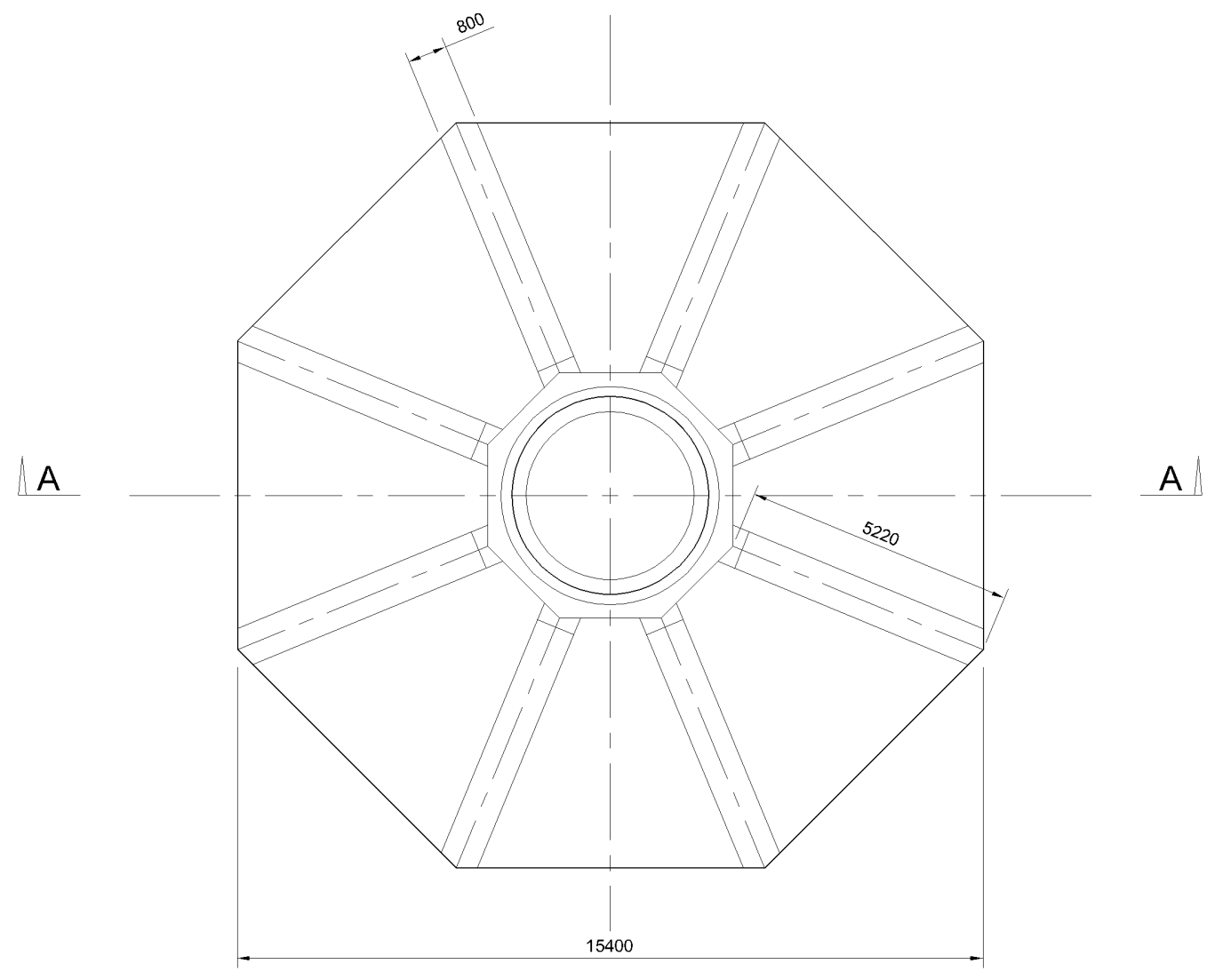

335

336

337

338

339

340

341

342

343

344

Plan

A

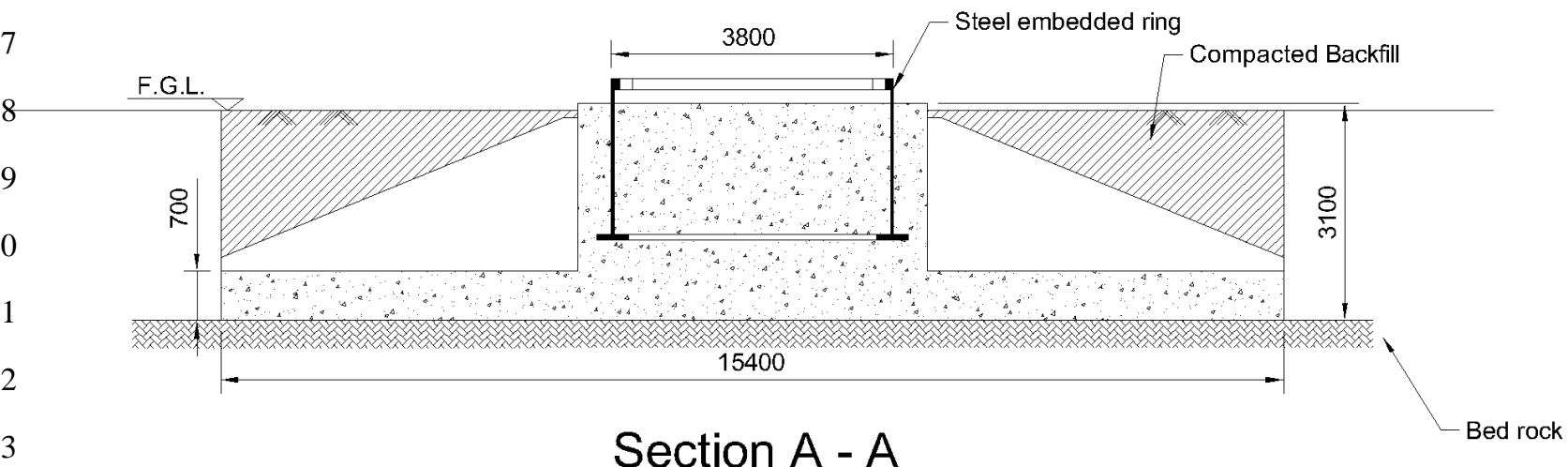

Fig. 3. Layout of the wind turbine concrete foundation (dimensions in $\mathrm{mm}$ ) 
a)

354

355

356

365

366

367

368

369
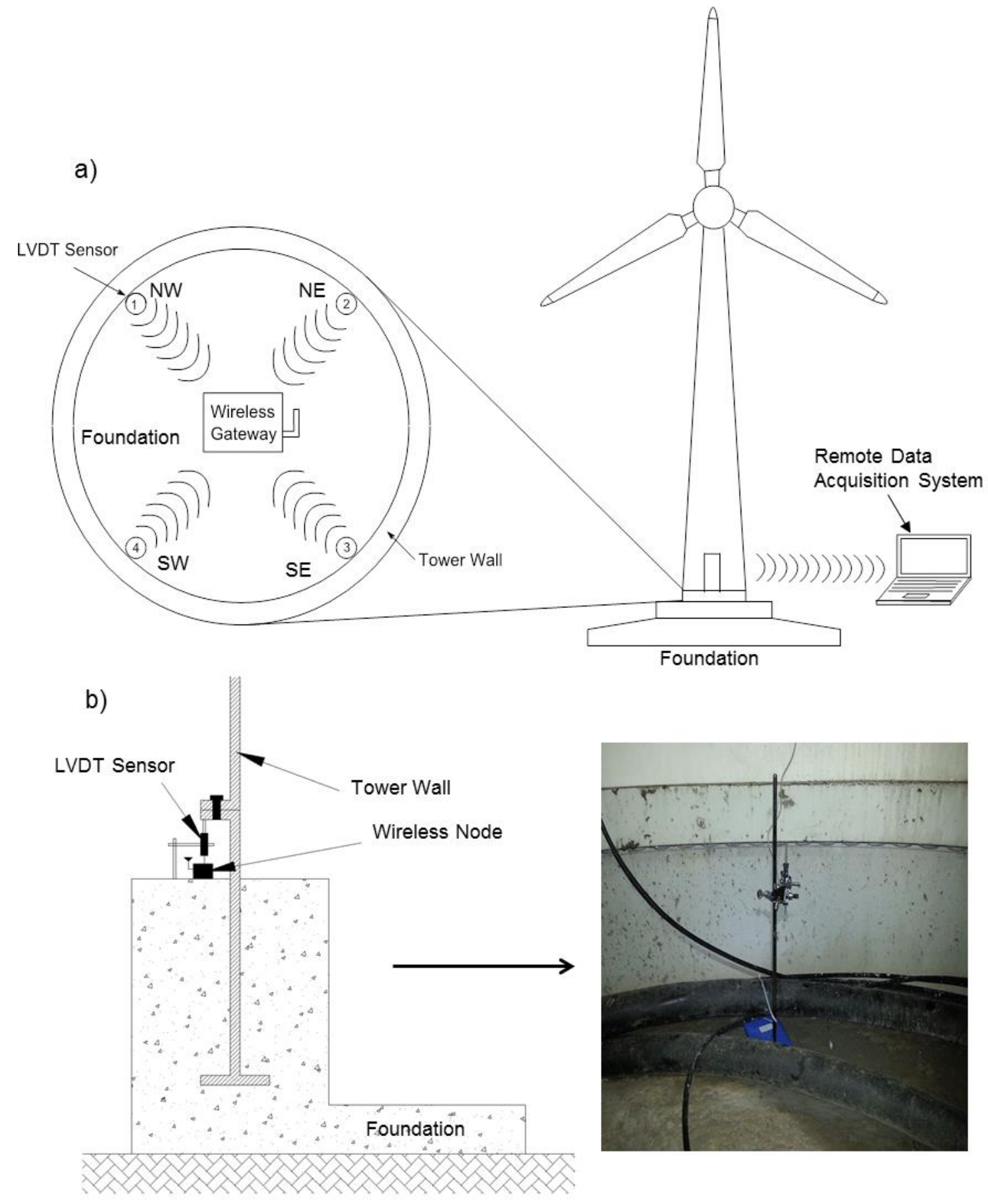

Fig. 4. a) SIM architecture and b) sensor installation. 
401

402

403

404

405

406

407

408

409

410

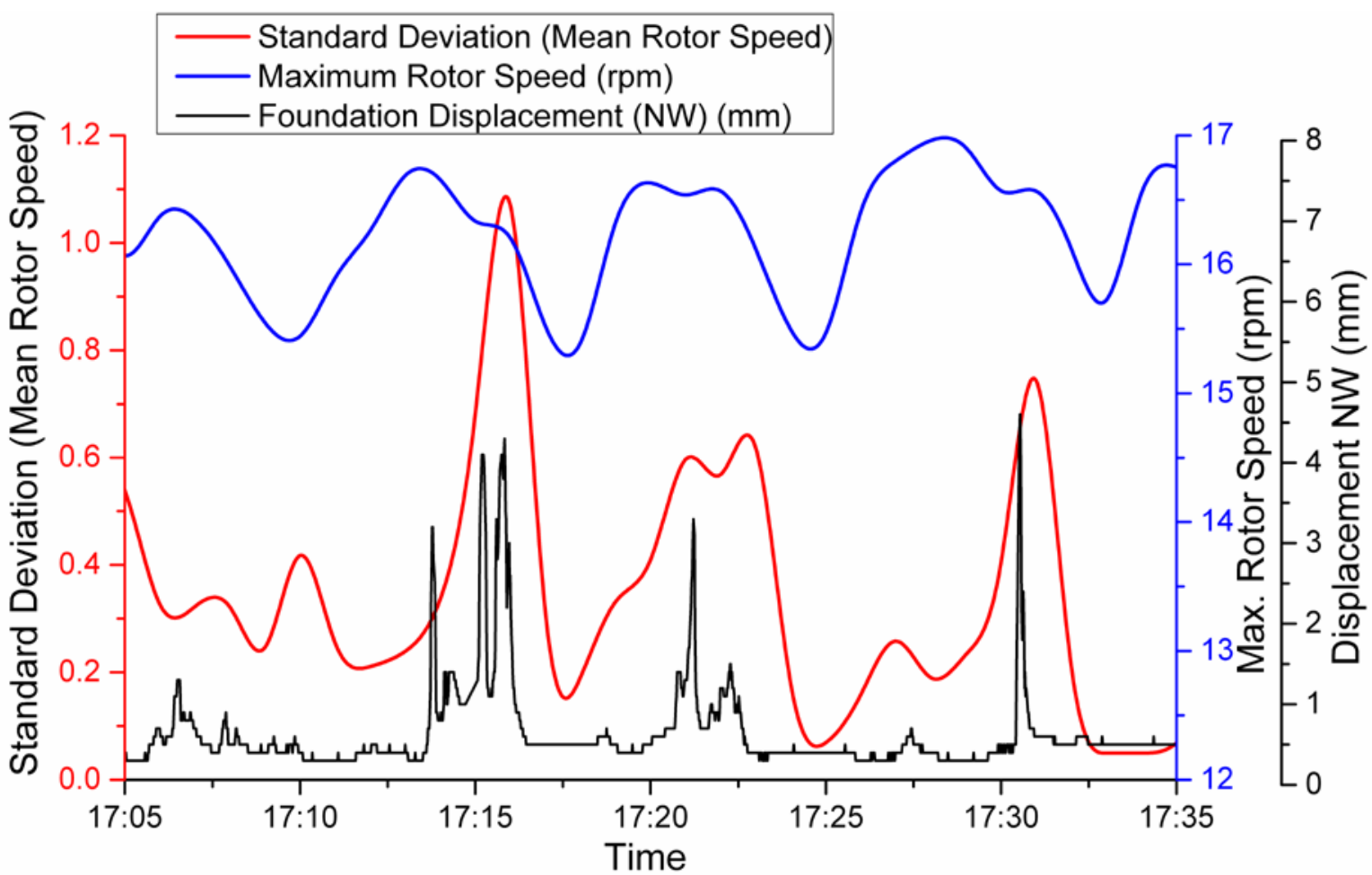

b) $\begin{aligned} & \text { Standard Deviation (Mean Rotor Speed) } \\ & \text { - Maximum Rotor Speed (RPM) } \\ & \text { - Displacement NW (mm) }\end{aligned}$

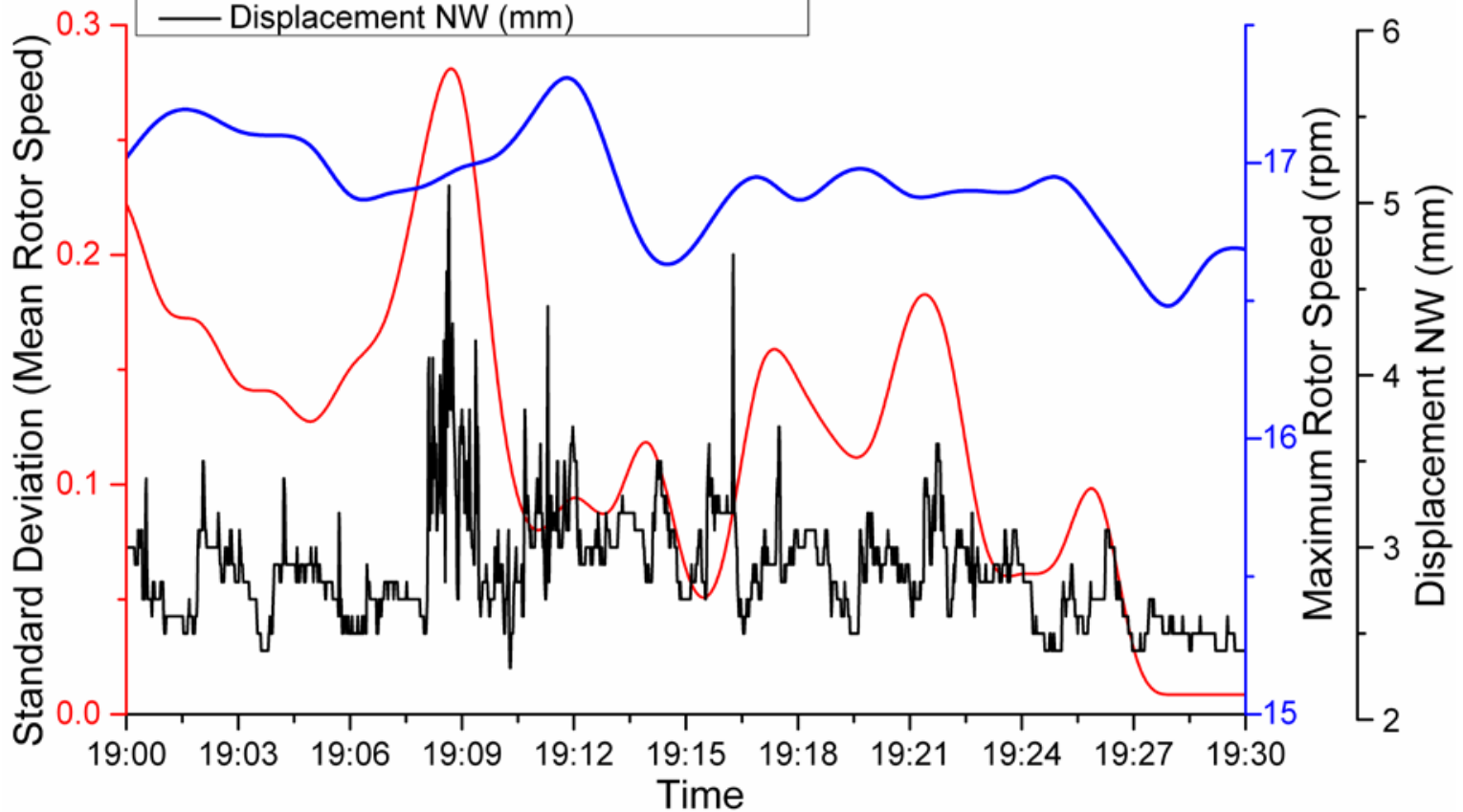


Fig. 5. Effect of rotor speed on the vertical displacement of the embedded ring.

414

415

416

417

418

419

420

421

422

423

424

425

426

427

428

429

430

431

432

433

434

435

436

437

438

439

440

441
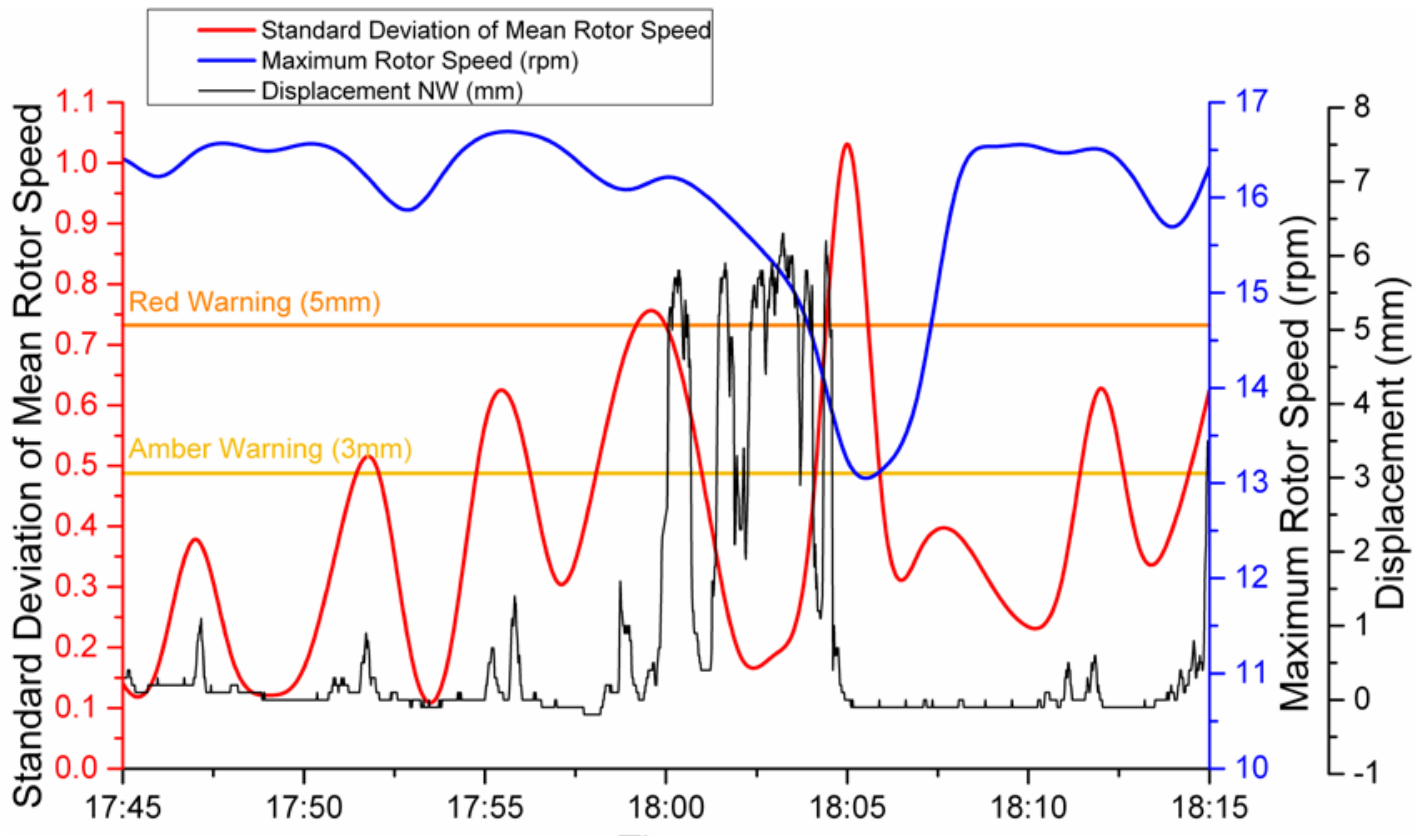

Time

Fig. 6. Effect of high wind speed on the vertical displacement of the embedded ring.

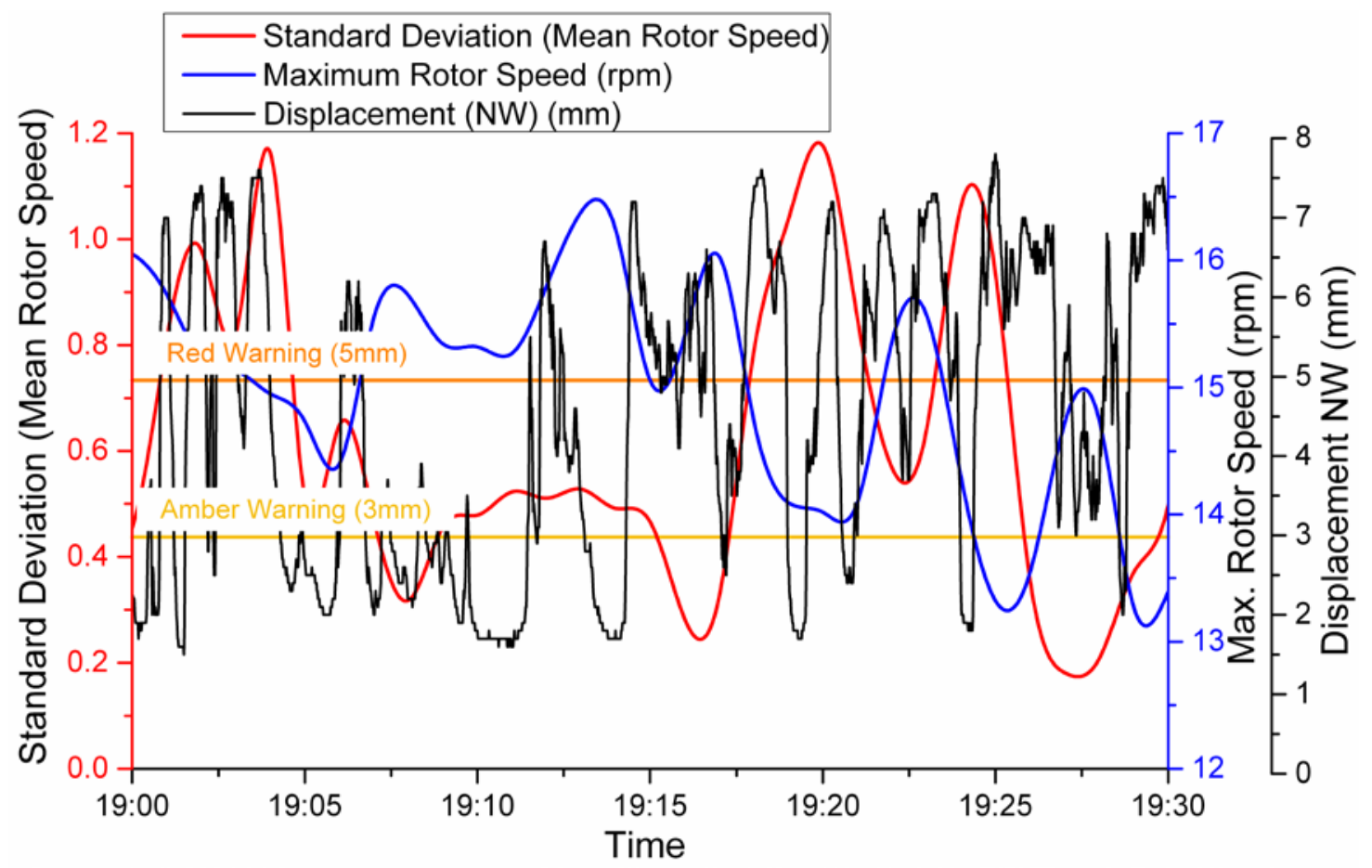


Fig. 7. Cyclic vertical displacement of the embedded ring as a result of high wind speed.

445

446

447

448

449

450

451

452

453

454

455

456

457

458

459

460

461

462

463

464

465

466

467

468

469

470

471

472

a)

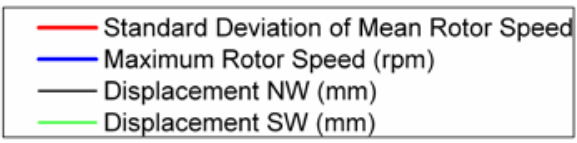

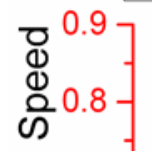

음 0.7 -

$\frac{\pi}{\overline{0}} 0.6-1$

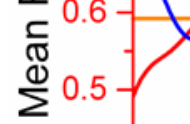

웅 0.4

을 0.3 -

ठิ $0.2-1$

은 0.1 -

志 0.0 -

19:10

\section{Time}

b)
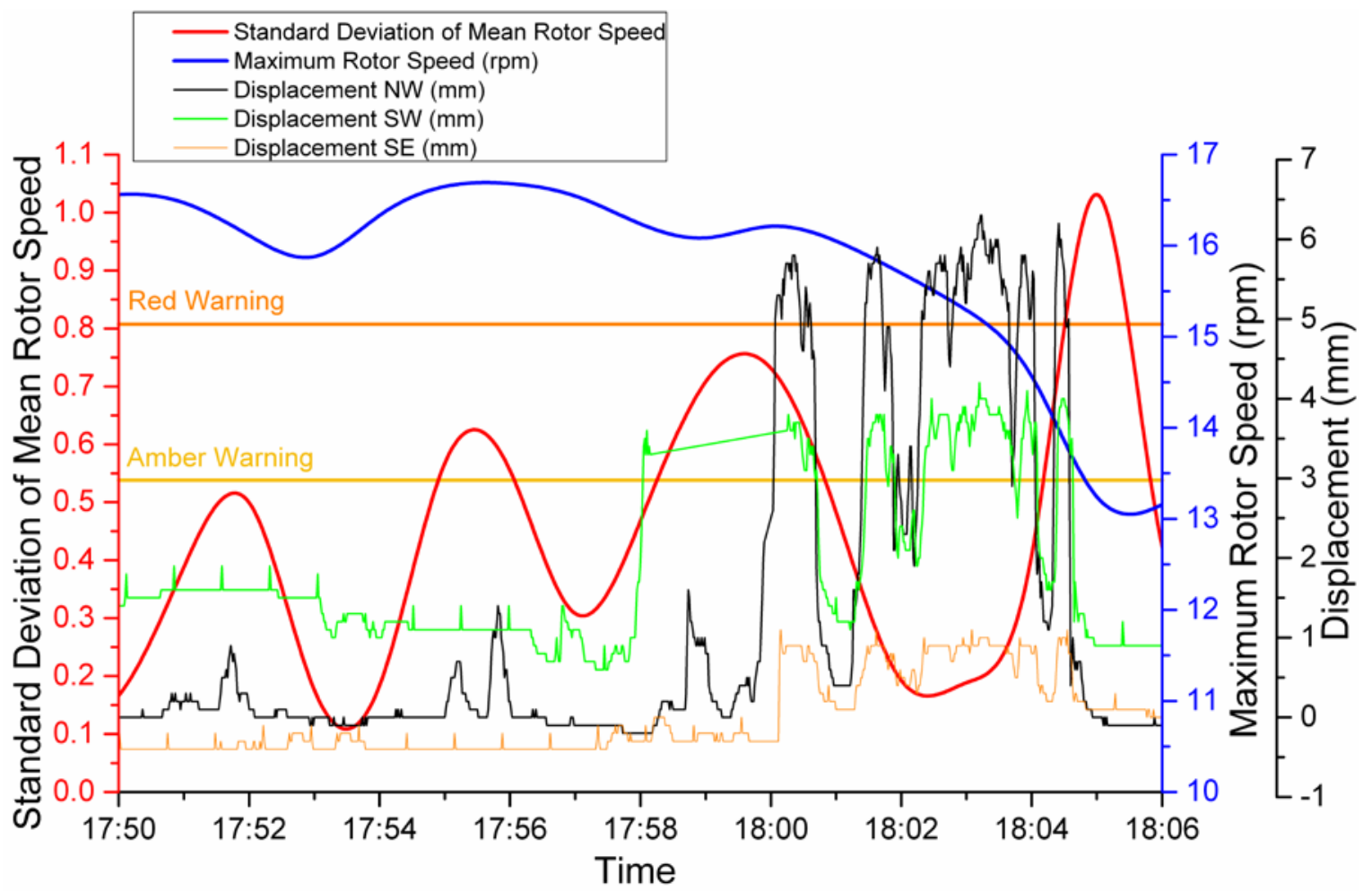
475 Fig. 8: Effect of wind direction on the vertical displacement of the embedded ring a) comparison 476 between NW and SW sensors, b) comparison between NW, SW and SE sensors during a major 477 change in the rotor speed. 